\title{
As Escolas de Investigação em Química, em Paris, na segunda metade do séc. XIX
}

\author{
A NA CARNEIRO*
}

\begin{abstract}
Sumário
Sendo uma criação do séc. XIX, as escolas de investigação vieram a ter um papel decisivo na profissionalização da investigação científica. Este artigo pretende caracterizar as escolas de investigação lideradas por Auguste Cahours (1813-1891), Henri Sante-Claire Deville (1818-1881), Adolphe Wurtz (1817-1884), Louis Pasteur (1822-1895), e Marcelin Berthelot (1827-1907) e analisar de que modo contribuiram para instalar a investigação na vida universitária francesa.
\end{abstract}

\section{Introdução}

Numa altura em que a Inglaterra, a Prússia, os Estados Germânicos e a Rússia se esforçam por dotar o ensino universitário de um luxo pouco usual, certamente, o Sr. Ministro não gostaria que a Faculdade de Ciências ficasse para trás neste nobre movimento do espirito humano

(Jean-Baptiste Dumas, 1840)

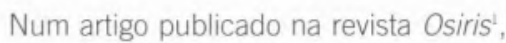
John Servos faz uma revisão do conceito de escola de investigação concluindo que, desde o séc. XIX, a palavra escola faz parte do vocabulário dos cientistas. Pode considerar-se que a entidade escola é, fundamentalmente, uma criação daquele século, que coincidiu, por um lado, com uma maior massificação do ensino superior e, por outro, com uma especialização crescente. A escola constituiu, assim, uma importante peça de maquinaria no processo que transformou a ciência num empreendimento colectivo.
Mais recentemente, em vez da palavra escola, os historiadores da ciência têm usado expressões como escola de investigação ou grupo de investigação como categorias de análise histórica. A primeira foi estabelecida pelos trabalhos já clássicos de Morrell ${ }^{2}$ e Geison ${ }^{3}$, e a última foi sugerida por Fruton ${ }^{4}$ como uma expressão mais adequada. Todavia, enquanto categorias históricas de inegável utilidade sāo, inevitavelmente, abstracções e prestam-se a alguma confusão. Apesar dos seus autores nunca terem reivindicado a universalidade de tais conceitos o facto é que eles tendem, frequentemente, a deixar ocultas características especificas de contextos científicos, sociais e culturais localizados no espaço e no tempo. De facto, a busca essencialista de um conceito universal de escola de investigaçẫo ou de grupo de investigação definidos sem atender a contextos locais, estilos nacionais e momentos históricos, parece um tanto inútil. Enquanto abstracçōes, estas categorias e critérios deverão antes ser tomados como linhas de orientação flexíveis em vez de "réguas" absolutas relativamente às quais se mediriam as diferentes formas de organização colectiva no seio de uma comunidade científica.

As condições para a emergência de escolas no séc. XIX situam-se, em larga medida, nos princípios advogados por Naturphilosophen como Schelling (1775-1854), Fichte (1762-1814) e Schleiermacher (1768-1834) $)^{5}$. Nomeadamente, a publicação por Schelling da obra Vorlesung über die Method des Akademischen Studiums, em 1803, veio a ter um papel de relevo na reforma das universidades dos Estados germânicos. Schelling defendia que o objectivo das universidades era a procura da verdade, no quadro de uma concepção holistica do conhecimento (Wissenschaft), que o papel do professor universitário não era a transmissão de factos, mas o de iniciar os estudantes nos métodos da investigação e da crítica, e tanto o ensino como a aprendizagem não deveriam estar sujeitos a quaisquer restriçōes, Lehrn- und Lehrfreiheit ${ }^{6}$. Estavam assim enunciados alguns dos princípios que trouxeram a investigação para o centro das universidades alemãs. Estes princípios foram reforçados por um revivalismo das práticas medievais tão do agrado de muitos românticos, nas quais as guildas e a unversitas medievais forneciam uma inspiração tanto para o professor enquanto Meister orientando descobertas originais, como para o aluno enquanto aprendiz no quadro de um processo de Bildung ${ }^{7}$. Ideais semelhantes foram também veiculados em obras literárias que ajudaram a propagá-los como é o caso de Wilhelm Meisters Lehrjahre (1795-1796) de Goethe (1749-1832), e Die Lehrlinge zu Sais (1802) de Novalis $(1772-1801)^{8}$

Em 1805, Fichte também contribuiria para a filosofia desta reforma defendendo que as universidades deveriam produzir em vez de reproduzir conhecimento, e que os resultados das investigações deveriam ser publicados pelo que as universidades deveriam possuir canais próprios para esse efeito. Fichte deu ênfase especial ao professor universitário, tecendo considerações 
sobre o modo como deveria ser formado, sobre o seu papel enquanto educador e, muito especialmente, enquanto criador $^{5}$. No que se refere aos estudantes defendia que estes não deveriam confinar-se à universidade onde se formavam, mas deveriam viajar e frequentar outras, por forma a alargar os horizontes, evitar nacionalismos e desenvolver uma perspectiva internacional do conhecimento.

Também por esta altura Schleiermacher criticava o modelo centralista, autoritário e burocrático que Napoleão I tinha instituído no ensino superior francês e sugeria, como alternativa, um outro baseado na relação cooperativa professor/aluno, envolvendo colaboração, respeito mútuo e liberdade individual ${ }^{10}$. Mais tarde, em pleno terceiro quartel do séc. XIX, Hermann von Helmoltz (1821-1894) criticava as universidades francesas argumentando que estas estavam amarradas a programas rigidos, contemplavam apenas o ensino de matérias completamente conhecidas, deixando de parte questões controversas ou incompletamente compreendidas. Para Helmoltz, as universidades francesas não tinham em conta as capacidades crítica e de descoberta tanto dos professores como dos alunos: os primeiros tinham de possuir um vasto acúmulo de conhecimentos; os segundos eram apenas ensinados para passar em exames exigentes ${ }^{11}$.

Decorreram assim da Naturphilosophie e do movimento romântico as bases ideológicas da reforma que, posteriormente, levou à emergência de escolas de investigação das quais a de Justus von Liebig (1803-1873) na Universidade Giessen (1824) se tornou paradigmática. Esta escola serviu de modelo a muitas outras criadas por toda a Europa, votadas à investigação química ou a outras áreas do saber ${ }^{12}$. Apesar da rejeição formal da Naturphilosophie por parte de Liebig, tanto a organização da sua escola de investigação como a sua prática científica, retiveram muitos dos pressupostos advogados pelos Naturphilosophen $^{13}$. Em particular, o estágio de investigação era concebido como parte da educação/formaçâo e não como um estádio inicial de uma carreira; os alunos

pagavam uma propina para custear as despesas do estágio; a publicação dos resultados era fortemente encorajada, pelo que a escola de Liebig passou a controlar uma revista, os Annalen der Chimie und Pharmacie, também conhecidos por Liebig Annalen; era dado ênfase às capacidades de cada um, pelo que os discípulos publicavam em nome individual os seus trabalhos; praticava-se a cooperação entre os discípulos dentro do laboratório; havia uma forte dimensão cosmopolita, ilustrada pelas muitas nacionalidades dos discipulos de Liebig $^{14}$.

Pouco depois de Liebig, Jean-Baptiste André Dumas (1800-1884) seguir-lhe-ia o exemplo no seu laboratório particular em Paris, acontecimento que marca, até certo ponto, a transposição do modelo alemão para a cena francesa ${ }^{15}$. Esta escola apresenta, inevitavelmente, caracteristicas diferentes da sua correspondente germânica: não se situava numa instituição universitária, embora Dumas tivesse instado o Ministro da Instrução a criar um laboratório de investigação na Sorbonne; o estilo de liderança era mais controlador; as publicações dos discípulos eram feitas em co-autoria com Dumas, uma prática que Liebig criticou veementemente; estava mais confinada ao contexto francês, embora o laboratório de Dumas tenha sido fre- quentado por alguns estudantes estrangeiros.

\section{Escolas: mestres, alunos e doutrinas químicas}

Já há muito que o Senhor Liebig reuniu em Giessen estudantes vindos de todo o mundo e fundou uma escola justamente famosa. Desde ai, o estudo da quimica desenvolveu-se extraordinariamente na Alemanha. Foram construidos grandes laboratórios em Giessen, Heidelberg, Breslau, Göttingen. Karlsruhe e Greifswald que só trouxeram proveito à ciência. A Alemanha está justamente orgulhosa e duplica o seu esforço para elevar ainda mais os padrões do ensino da química prática, de acordo com os requisitos modernos.

(Adolphe Wurtz, 1864)

Em seguida, será analisado como é que a geração seguinte à de Dumas e de Liebig e por eles inspirada, organizou a investigação química no contexto do ensino superior, em Paris, a partir da segunda metade do século.

Nesta secção as várias escolas não serão tratadas de forma exaustiva por razōes de espaço. Apenas se fará ressaltar algumas das suas principais características por forma a caracterizá-las minimamente ${ }^{i b}$. A sua apresentação 
será cronológica de modo a acompanhar-se a evolução do processo que levou à instalação da investigação no ensino superior e à profissionalização da investigação química em França, ou melhor, em Paris, dado o lugar geralmente secundário das universidades de província, muito em especial nesta matéria.

Durante o Segundo Império, o xadrez da química francesa era dominado por Dumas, justificando-se o epíteto irónico l'Être suprême dado por Gustave Quesneville (1810-1889), editor da revista Moniteur Scientifique ${ }^{17}$. Um parte deste poder distribuía-se depois pelos quími$\cos$ que gravitavam à sua volta: Cahours, Deville, Wurtz, Pasteur ${ }^{18}$, Berthelot, cada um liderando uma escola de investigação. Com a excepção de Berthelot todos tinham sido seus discipulos.

A ascensão de Dumas deveu-se a dois factores principais: ele próprio ter sido um prestigiado e influente chef d'école, e ter ocupado vários cargos políticos e administrativos no quadro do Ministério da Instruçāo, vindo posteriormente a ser Ministro da Agricultura. Estava assim em posição de favorecer e proteger de forma singular o estabelecimento de escolas de investigação em química nas principais instituições de ensino superior de Paris, onde aliás tinha leccionado.

\section{A escola de investigação de Auguste Cahours (1813-1891)}

Graduado da École Polytechnique (1835) e discípulo da escola de Dumas onde travou amizade com Deville e Wurtz, o reconhecimento científico de Cahours foi alcançado na àrea da química orgânica, quando investigou o "óleo de batata"(1829-1840), isolando o álcool amílico. Dumas comentou a este propósito que a descoberta de um novo álcool equivalia à descoberta de um novo metal na química mineral e, partir daí, tornou-se seu patrono ${ }^{19}$.

Em 1851, foi nomeado professor de química da École Polytecnique, substituindo Victor Regnault (1810-1878), antigo discípulo de Liebig e de Dumas, mas que nunca realizou investigação quími- ca nesta grande école. Através do regime de cumul e suppléance ${ }^{20}$, Cahours sucedeu a Dumas na École des Arts et Manufactures (1852) e foi seu suppléant na Sorbonne (1851-1853). Ao prestígio inerente ao lugar de professor da École Polytechnique (1851-1881), juntou a eleição para a Académie des Sciences em 1868, aumentando assim a sua influência no meio académico e a capacidade de ele próprio se tornar um patrono.

Cahours é retratado pelos seus discípulos como um mestre paternal, afável e com sentido de humor, características ausentes das descrições de vários dos

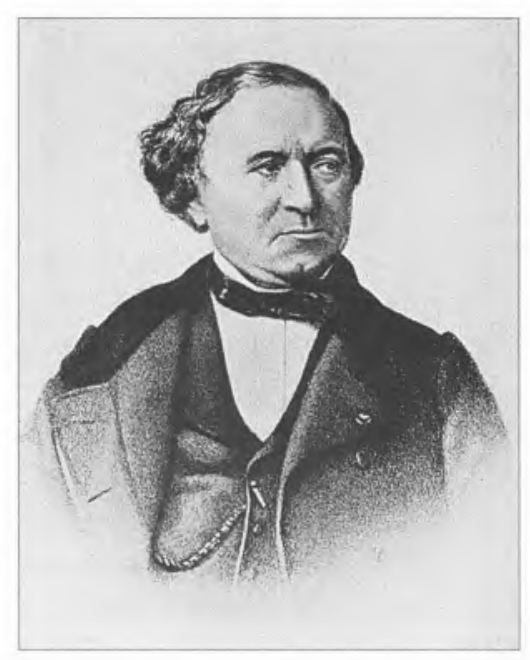

Jean Baptiste Dumas

seus colegas. A atmosfera do laboratório é descrita como franca, agradável e animada. A escola de Cahours não dispunha de um orçamento oficial para custear reagentes, material de laboratório ou investigadores. Os custos da investigação eram suportados pelas verbas destinadas ao ensino experimental das licenciaturas e pelo próprio mestre. Os discípulos eram recrutados usando os lugares disponiveis de répétiteur ou préparateur, que só implicavam actividades de ensino, sugerindo que a sua selecção se baseava no desejo que manifestassem de enveredar pela investigação. De Cahours apenas foram identificados seis discípulos cujas carreiras mostram alguma sobreposição entre esta escola e a de Wurtz relativamente à teoria quimi$\mathrm{ca}$, a iniciativas associativas e editoriais, e ao próprio patrocínio. No que se refere à teoria a posição de Cahours é um tanto ambivalente. A investigação, fundamentalmente em compostos orgânicos e organometálicos, desenvolveu-se no quadro da teoria atómica. Embora aconselhasse os discípulos a segui-la, ele próprio não ousava apresentar nos seus artigos as fórmulas químicas na notação atómica pois receava desafiar a autoridade de Dumas e a ciência oficial que the eram claramente desfavoráveis ${ }^{22}$.

Mestre e discípulos publicavam regularmente nos prestigiados Comptes Rendus da Académie des Sciences, Annales de Chimie e no Bulletin da Société Chimique, e em média após a publicação de dois ou três artigos em co-autoria com o mestre, passavam a publicar autonomamente.

A escola de Cahours participou na fundação da Société Chimique de France, criada em 1863, na sua direcção e no corpo redactorial do Bulletin, em colaboração com os discípulos de Wurtz ${ }^{72}$.

\section{A escola de Henri Sainte-Claire Deville (1818-1881)}

Talvez o discípulo predilecto de Dumas já que inspirou neste o retrato do chef $d^{\prime \prime}$ école ideal ${ }^{24}$, estudou medicina antes de se tornar químico. Iniciou-se no laboratório de Dumas onde obteve derivados de terpenos e realizou investigaçōes sobre o tolueno (1840-1842), trabalhos que Ihe trouxeram notoriedade. Apesar de se ter iniciado na química orgânica, então em fase de grande expansão, Deville veio a optar pela química mineral e por algumas aplicações da química, distanciando-se assim dos mais directos competidores. Com o patrocinio de Dumas foi nomeado, em 1851, professor de quimica da outra grande école, a Ecole Normale, que formava a maioria dos professores dos liceus. Durante 13 anos foi ainda suppléant de Dumas na Sorbonne, sendo eleito para a seç̧ão de mineralogia da Académie des Sciences em 1861. Apesar de não se ter envolvido directamente em actividades politicas, como era tão comum no meio cientifico francês, Deville apoiava o Segundo 
Império e com o patrocínio de Dumas e de Napoleão III fez parte da administração da companhia de gás de Paris e da companhia de caminho de ferro do Este.

Deville é descrito pelos seus discípulos como uma figura paternalista, entusiasta, e incansável votada a trabalhos penosos e perigosos ${ }^{25}$, constituindo-se como um padrāo moral a ser seguido pelos mais jovens, dado que a sua devoção científica era considerada uma verdadeira manifestação de patriotis$\mathrm{mo}^{26}$

No que se refere ao financiamento, não se limitou como Cahours ao orçamento destinado ao ensino laboratorial dos alunos de licenciatura e à contratação de préparateurs. Através da influência de Dumas, do Imperador e da Académie, obteve fundos que the permitiram instalar na École Normale o laboratório de investigaçăo mais bem equipado existente em Paris o que determinou, em grande medida, a sua capacidade de recrutar discipulos. Estes podem dividir-se em Normaliens, seleccionados entre licenciados da École Normale, e non-Normaliens, entre os quais estavam os dois estrangeiros que frequentaram o laboratório. De um total de 30, cerca de 2/3 realizaram doutoramentos, enquanto desempenhavam funções de agrégé-préparateur. Sob o patrocínio de Deville obtinham, posteriormente, lugares em Faculdades de provincia ou em Paris. Deste modo, pode afirmar-se que esta escola detinha o controlo do ensino da química tanto no secundário como em grande parte do ensino superior ${ }^{27}$.

A prática química de Deville estava impregnada de princípios de inspiração positivista, embora nunca o tivesse admitido explicitamente. Considerava a química uma ciência natural que deveria estar subordinada às leis da física macroscópica, mas ao contrário de Auguste Comte (1798-1857), rejeitava o valor de teorias e hipóteses ${ }^{28}$. Opunha-se, por isso, à teoria atómica por considerá-la especulativa. Basicamente um experimentalista, iniciou a sua pesquisa em química mineral nos anos $40 \mathrm{da}$ qual resultou, em 1855, um processo de obtenção do alumínio metálico através da redução dos seus sais pelo sódio. Com este trabalho reduziu os custos de produção deste metal o que impressionou grandemente Napoleão III e foi decisivo para continuar a ter o seu apoio ${ }^{2}$. Os seus discípulos participaram das investigações de Deville quer no âmbito da química mineral quer no da química-física das quais se destacam o estudo dos metais do grupo da platina (1859-1862), a preparaçăo de minerais artificiais, desenvolvimento de técnicas, em particular fornos de altas temperaturas, e as experiências que conduziram ao princípio de dissociação, em 1857.

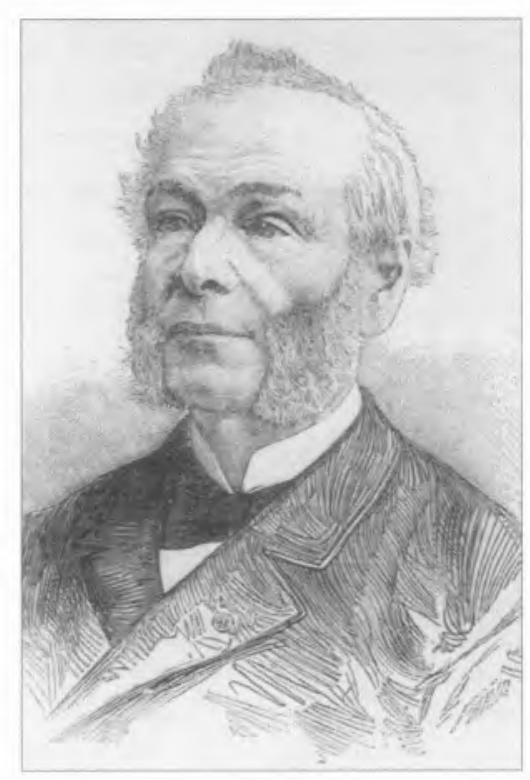

Adolphe Wurtz

Deville publicou uma quantidade significativa de artigos com os discípulos especialmente os do "núcleo duro," i. e., aqueles que permaneceram até à morte do mestre sob a sua tutela. A publicação independente de artigos pelos estagiários é pouco expressiva. A escola de Deville nunca controlou nenhuma revista científica, publicando principalmente nos Comptes Rendus da Académie des Sciences e nos Annales de Chimie. Deville participou na fundação da Société Chimique e, tal como alguns dos seus discípulos mais chegados, foi presidente, embora só raramente tenha publicado na revista desta organização.

\section{A escola de Adolphe Wurtz (1813-1884)}

Adolphe Wurtz nasceu em Estrasburgo no seio de uma família luterana. Depois de concluir o ensino secundário no Ginásio luterano de Estrasburgo, cursou e doutorou-se na Faculdade de Medicina local em 1843, seguindo depois para Giessen para estagiar no laboratório de Liebig. Ai travou conhecimento com vários químicos estrangeiros que viriam a notabilizar-se na química orgânica do séc. XIX. Tal como fizera com o seu colega do Ginásio, Charles Gerhardt (1816-1856), Liebig confiou-Ihe a tradução dos artigos para francês destinados aos Annales de Chimie, pondo assim Wurtz em contacto com os principais químicos franceses, em particular Dumas, então editor daquela revista.

Depois de uma viagem que incluiu Viena e Londres, onde o seu cunhado exercia funções de curador da colecção de pintura do Príncipe Albert, Wurtz chega a Paris com cartas de recomendação de Liebig para Dumas, que o recebe no seu laboratório ${ }^{20}$. Aqui continuou os trabalhos iniciados em Giessen sobre os ácidos do fósforo (1842-1845). Em 1845 é nomeado préparateur de Dumas na Faculdade de Medicina e chef de travaux chimiques na Ecole Centrale des Arts et Manufactures. Em 1850 efectua estudos sobre o álcool butílico e até 1853 conclui a investigação sobre os derivados do cianogénio. Todos estes trabalhos conduziram a conclusões com impacto teórico: mostraram que o hidrogénio presente num ácido não determina a sua basicidade como então se pensava, e que a basicidade de um dado radical é tanto maior quanto maior for o seu conteúdo em oxigénio. Em 1844, a partir de uma investigação sobre o hidreto de cobre concluiu que o hidrogénio gasoso, libertado pela adição de ácido clorídrico, é diatómico $\left(\mathrm{H}_{2}\right)$ e não monoatómico $(\mathrm{H})$ como era aceite ${ }^{31}$. Entre 1844-45 traduz para alemão o livro de Gerhardt, Précis de Chimie Organique, onde este sistematiza a sua teoria dos tipos e uma nova nomenclatura cuja exploração irá servir de base à investigação desenvolvida na escola de Wurtz, já que Gerhardt morre prematuramente. 
Em 1849, Wurtz é nomeado suppléant de Dumas e, em 1853, professor de química da Faculdade de Medicina, onde irá instalar um laboratório de investigação.

Apesar de não dispor de qualquer orçamento oficial para a investigação e, um tanto esquecido por Dumas, como anos antes o autor do célebre pêndulo Léon Foucault (1819-1868) já tinha feito notar ${ }^{32}$, Wurtz decide-se por uma soluçāo original no contexto francês. Com ela irá preservar a sua independência face aos poderes estabelecidos, não sendo obrigado a orientar a investigação pessoal e a da escola segundo interesses políticos e económicos como aconteceu com Deville e Pasteur. A semeIhança de Liebig e do que era a prática alemã, irá cobrar aos discípulos uma propina destinada a custear as despesas laboratoriais. Propina que poderia ser reduzida ou suprimida em caso de dificuldades financeiras por parte de um estudante talentoso. Wurtz também isentava desse pagamento qualquer discípulo que publicasse um trabalho de particular relevo numa revista de prestigio. O recrutamento de discípulos mais de centena e meia ao longo dos trinta anos do laboratório - fez-se, essencialmente, entre licenciados calvinistas e luteranos originários de famílias ligadas à florescente comunidade industrial da Alsácia ${ }^{33}$, e nos meios científicos internacionais, em especial, laboratórios de investigação situados em universidades dos Estados Germânicos, Império Austro-Húngaro, Grã-Bretanha e Rússia. De entre os discípulos pode identificar-se um núcleo duro, formado por uma ala académica e por outra industrial. Este núcleo era essencialmente composto de franceses, a maior parte de origem alsaciana. Entre eles contavam-se alguns marginais ao sistema académico como Joseph Achille Le Bel (1847-1930) e Auguste Scheurer-Kesther (1833-1889) que rejeitavam abertamente as praxes cientificas oficiais, ou o socialista Alfred Naquet (1834-1916). Os dois últimos viriam a envolver-se no famoso affaire Dreyfus, questão que dividiria de forma drástica a intelligentsia francesa $a^{34}$.
Só os discípulos de nacionalidade francesa realizaram doutoramentos. Para os estrangeiros a obtenção deste grau tornava-se complicada, já que a burocracia exigia habilitações adquiridas no sistema de ensino francês. Normalmente, efectuavam o doutoramento na Alemanha e depois vinham para o laboratório de Wurtz para um estágio que consideravam de aperfeiçoamento. Por razões culturais, os discipulos entendiam o estágio como parte da sua educação e portanto, o pagamento do mesmo era feito com toda a naturalidade. Quando Dumas se deu conta desta situação "ilegal" - um espaço num edifício pública governado por fundos privados - pediu a Wurtz uma explicação detalhada sobre o funcionamento e resultados do laboratório. Não encontrando nenhuma irregularidade, concluiu ser tarde demais para inverter o processo, dada a projecção internacional que a escola entretanto alcançara ${ }^{35}$. Pode assim afirmar-se que, enquanto mestre, Wurtz se impôs pelo exterior para depois se impor em Paris. A atestá-lo está ainda o facto de que ao contrário dos seus colegas, antes de ser eleito para a Académie des Sciences, secção de química (1867), já era membro da Royal Society (1864) e de outras academias estrangeiras. A sua ascensão dentro do sistema não fugiu à regra e foi marcada por nomeações para cargos importantes e distinções que se revelaram fundamentais para a sobrevivência e desenvolvimento de uma escola com características tão sui generis quanto a sua. A semelhança dos colegas, obteve prémios científicos da Académie e os vários graus da indispensável Légion d'Honneur. Foi ainda nomeado Deão da Faculdade de Medicina (1864-1875), onde introduziu inovações no modo de funcionamento: defendia a liberdade de expressão e, por sua iniciativa, foi nesta Faculdade que, pela primeira vez, foram admitidas muIheres no ensino superior francês ${ }^{36}$. Em 1875 , foi nomeado professor de química orgânica na Sorbonne, e em 1880 eleito para o Senado como membro da ala centro-esquerda do Partido Republicano. Considerado um conservador, defendia a iniciativa privada, rejeitava o proteccionismo do estado e as atitudes de extremo nacionalismo as quais, no seu entender, levariam a França ao isolamento.

Wurtz é descrito pelos discipulos em termos distintos do usual. É retratado como uma pessoa robusta, alegre, com uma fisionomia expressiva e grande poder de comunicação. Praticava ginástica e, frequentemente, emprestava a sua voz de barítono a eventos musicais organizados por estudantes e músicos amadores $^{37}$. Não the sendo conferidos atributos paternais ou paternalistas, é antes descrito como um colega mais experiente, mas disposto a aprender com os seus pupilos em áreas que estes pudessem conhecer melhor. A atmosfera do laboratório é descrita como muito animada, interessando-se o mestre mais pelas ideias dos jovens investigadores e pela qualidade dos resultados do que pela quantidade de trabalho por eles efectuada ${ }^{38}$.

A escola defendia o atomismo situando-se a maior parte da investigação na transição entre a teoria dos tipos e a química estrutural. Vários dos seus alunos dedicaram-se também a aplicações da química (pigmentos de uso industrial, caracterização de águas minerais e química biológica) e ainda a estudos de espectroscopia.

Com base na teoria dos tipos foram previstos teoricamente, sintetizados e formulados inúmeros compostos orgânicos sendo o mote dado pelo próprio mestre. Em 1856, previu teoricamente a existência do glicol como sendo o composto que ocupava a posição intermédia da escala que se iniciava com o etanol e que continuava depois com a glicerina. Wurtz defendia a unificação da química pelas regras da química orgânica e, com o seu amigo August Kekulé (1829-1896), foi um dos organizadores do Congresso de Karlsruhe em 1860, onde foi discutida a redefinição e normalização de conceitos químicos com base na teoria atómica. Enquanto representante do atomismo em França é desafiado em 1877 para uma controvérsia na Académie des Sciences desencadeada por Louis Troost (1825-1911), um discípulo de Deville. No entanto, rapidamente Berthelot assume as rédeas da oposi- 
ção. No final, ambos permaneceram irredutíveis nos seus pressupostos ${ }^{39}$.

No que se refere a publicações, praticamente todos os discípulos publicaram durante o período de estágio pelo menos um artigo em nome individual, embora em nota referissem que o trabaIho tinha sido realizado no laboratório de Wurtz. Encorajava-se assim a produção, fomentando-se a responsabilidade e autonomia científica de cada um. Só um número ínfimo de artigos foi publicado em co-autoria com discípulos e só quando resultaram de uma colaboração efectiva $^{40}$.

Enquanto colectivo, a escola envolveu-se em várias actividades, algumas iniciativa do mestre e apoiadas pelos discipulos e o inverso. Assim, foi um grupo de jovens químicos integrando discipulos de Wurtz que lançou a ideia de criar a Société Chimique, uma instituição importante no reconhecimento formal da profissão de químico em França. O mestre deu prontamente a sua colaboração, obtendo o apoio de Dumas e dos colegas. Daqui em diante, todos os discípulos quando eram admitidos no laboratório tornavam-se, imediatamente, membros da Société.

Na verdade, a Société Chimique e o seu Bulletin vieram a ser controlados pela escola de Wurtz. Embora os outros chefs d'école assumissem regularmente - lugar simbólico da presidência, denotando as capacidades diplomáticas de Wurtz, a verdade é que a administração e a redacção do Bulletin eram asseguradas pela escola deste último, com a colaboração dos discípulos de Cahours e de alguns de Pasteur. O Bulletin rapidamente se converteu num porta voz do atomismo em França ${ }^{4 !}$.

Outra instituição à qual a escola de Wurtz deu um contributo de peso foi à Association Française pour l'Avancement des Sciences (AFAS). Criada no rescaldo do conflito Franco-Prussiano (1870-1871), que levou à anexação da Alsácia-Lorena pela Alemanha, a AFAS pretendia ser uma resposta à derrota francesa atribuída pela intelectualidade nacional a um alegado declínio científico do país ${ }^{42}$. A AFAS promovia trabalhos de investigação cientifica e, principalmente, a sua divulgação em reuniões alargadas ao grande público, realizadas anualmente em diferentes cidades. Seguindo o modelo da influente British Association for the Advancement of Science, criada em 1833 - por sua vez inspirada pela Gesellschaft Deutscher Naturforscher und Ärtze, fundada em $1828^{43}$ - a AFAS nunca veio a ter o relevo das suas congéneres pois quadrava-se mal com o centralismo e a macrocefalia parisiense.

A escola de Wurtz associou-se ainda à criação, em 1871, da École Alsacienne de Paris, uma escola bilingue (francês/alemão) inspirada no Ginásio de Estrasburgo e na pedagogia do humanista

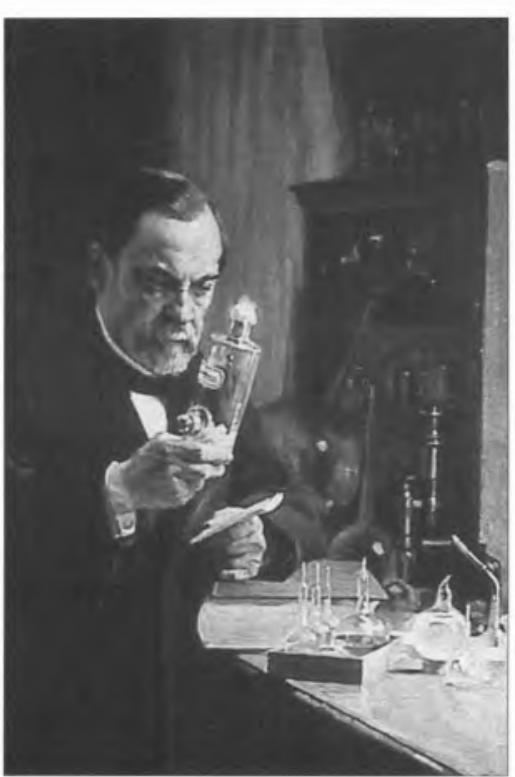

Louis Pasteur

morávio Comenius (1592-1670). Destinava-se à educação dos filhos dos refugiados alsacianos e a todos que, independente de credos políticos ou religiosos, aderissem a um projecto educativo que se pretendia demarcar dos rígidos lycées e dos colégios jesuitas ${ }^{44}$. Será também pela iniciativa de algunś antigos discípulos de Wurtz ligados à indústria que se irá criar no anos 80 a École Municipale de Chimie et de Physique Industrielles de la Ville de Paris. Inspirada na École Industrielle de Mulhouse (Alsácia) será a primeira escola superior oficial a formar engenheiros químicos, em França ${ }^{45}$

No que se refere à actividade editorial, para além da publicação regular pelos elementos da escola em revistas francesas e estrangeiras de renome, os discipulos de Wurtz ainda participaram activamente na ediçāo do Bulletin de la Société Chimique e no Dictionnaire de Chimie Pure et Appliquée (1869-1878) dirigido por ele. Iniciativa de alguns discipulos e apadrinhada pelo mestre, foi também a edição da Agenda du Chimiste, iniciada em 1876. Tratava-se de uma espécie de handbook para uso nos laboratórios de quimica e na indústria. Vários discipulos de Wurtz bem como ele próprio publicaram manuais de química seguindo a notação atómica, e ainda obras de história da química ${ }^{46}$

\section{A escola de Louis Pasteur (1822-1895)}

Embora nunca tenha frequentado o laboratório de Dumas, enquanto aluno da École Normale Pasteur foi atraído pelas lições de química de Dumas na Sorbonne. A partir dai considerou-se seu discipulo. Pasteur começou por trabalhar em cristalografia com Jean-Baptiste Biot (1774-1862) e com Auguste Laurent (1807-1853). Depois de terminar o doutoramento ensinou nas universidades de Estrasburgo (1849-1854) e Lille (1854-1857). Em 1857, sob o patrocínio de Dumas foi nomeado director de estudos da École Normale, lugar do qual viria a ser demitido em 1867, pela sua rigidez e impopularidade entre os estudantes. A título de compensação foi nomeado administrador da mesma escola, professor de química na Sorbonne e sob os auspícios de Dumas, de Napoleão III, e do Ministério de Instrução foi-Ihe dada uma verba para instalar na École Normale um laboratório de investigação em química fisiológica. A este financiamento sucederam-se outros da iniciativa do próprio Imperador e de entidades oficias, graças à influência de Dumas ${ }^{47}$. Pasteur veio a ser eleito em 1862 para a secção de mineralogia da Académie des Sciences. 
A imagem de Pasteur deixada pelos discípulos mais chegados é a de um líder espiritual, empenhado no bem da humanidade, um apóstolo cuja fisionomia se comparava à de $\mathrm{S}$. Vicente de Paulo $^{48}$. Após a queda do Segundo Império e com o advento da Terceira República, agnóstica e crítica mordaz da Igreja de Roma, a vigilância aos católicos em posições chave no ensino superior era particularmente intensa. Sendo um católico fervoroso, Pasteur simbolizava o cientista que conseguia conciliar ciência e religião, numa época difícil para os católicos ${ }^{49}$.

0 recrutamento de discipulos nesta escola apresenta certas particularidades. Aparentemente, Pasteur pretendia através deles colmatar limitaçōes físicas decorrentes de um derrame cerebral ocorrido em 1860 que the paralisara o lado esquerdo, impedindo-o de realizar muito do trabalho laboratorial. Os cerca de 30 discípulos que passaram pelo seu laboratório eram, acima de tudo, os executantes do trabalho experimental. Quando em 1877 se moveu para dominios ligados à medicina, além da paralisia teve ainda de enfrentar o desconhecimento de assuntos médicos e veterinários além de que a vivissecção the repugnava ${ }^{50}$. Assim começou por recrutar näo só Normaliens, tal como Deville, mas também médicos. Contudo nằo os dirigia directamente, sendo os seus alunos mais dedicados Emile Duclaux (1840-1904), um Normalien, e Emile Roux (1853-1933), um médico, que tinham essa função.

Segundo as descriçōes dos discipulos o silêncio no laboratório era regra de ouro, a limpeza era escrupulosa devido ao temor que Pasteur tinha das infecções, e o conforto era considerado supérfluo ${ }^{51}$. 0 mestre não informava os discipulos do propósito das experiências que executavam, deixando-lhes, conforme referem, 0 desafio de adivinhar ${ }^{52}$. A investigação liderada por Pasteur incidiu sobre a fermentação, em particular os estudos sobre o vinagre, o vinho e a geração espontânea (1857-1865); as doenças dos bichos da seda, a pebrina e a flacidez (1865-1870); os estudos sobre as cervejas e os novos debates sobre a geração espontânea (1871-1876); a etiologia e a profilaxia das doenças infecciosas - antraz, cólera, erisipela dos suínos e raiva (1877-1895).

A publicação de artigos científicos pelos discípulos é uma questão difícil de determinar. Por exemplo, apesar de Duclaux ter colaborado permanentemente com Pasteur até à morte deste, os artigos sẫo apenas assinados pelo mestre o que sugere uma apropriação do trabaIho do colaborador. Roux, por outro lado, publicou muito poucos artigos antes de $1890 \mathrm{e}$, mesmo esses, foram em co-autoria com o mestre o que pode justificar a necessidade de aceitação deste na comunidade médica, onde encontrava bastante oposição. Todavia,

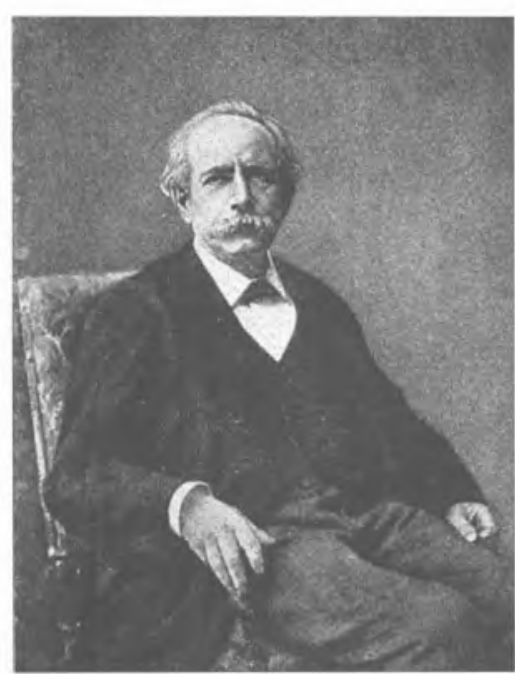

Marcelin Berthelot

nunca nenhum deles se queixou publicamente, apenas referem que Pasteur era muito cioso da prioridade de descoberta e da propriedade intelectual, e a mais leve crítica exasperava- $0^{53}$.

Pasteur participou na fundação da Société Chimique de France como primeiro vice-presidente e depois presidente. Alguns dos seus discípulos foram membros e colaboraram no corpo redactorial da revista desta instituição. Em 1888 foi criado o Institut Pasteur através de uma subscrição pública, nacional e internacional, já que Pasteur não queria de nenhuma forma ver-se associado ao governo republicano. A partir daí, a escola de
Pasteur controlou uma publicação, os Annales de l'Institut Pasteur, criada por Duclaux.

\section{A escola de Marcelin Berthelot (1827-1907)}

Berthelot nasceu numa familia burguesa de Paris e foi educado no mais estrito catolicismo o qual viria mais tarde a rejeitar, aderindo à ideologia positivista e tornando-se agnóstico. Ao contrário dos seus colegas, não frequentou nenhuma das grandes écoles, ou escola de investigação. Formou-se em farmácia em 1858, mas desde 1854 que desempenhava as funções de préparateur de Antoine Jerôme Balard (1802-1876), no Collège de France. Disposto a lutar por um lugar de destaque na cena química, quando as principais posiçōes no ensino superior estavam já tomadas, Berthelot persuadiu Balard a obter o apoio de Dumas e assim, em 1863, veio a ser nomeado pelo Ministro da Instrução, Victor Duruy (1811-1894), professor de química orgânica de um curso criado expressamente para ele, no prestigiado Collège de France. A manobra jornalistica que precedeu esta nomeação provocou a mais viva indignaçã̃o de Pasteur. que a considerou uma conspiração de positivistas, e de Wurtz porque o jovem e inexperiente Berthelot foi publicamente apresentado como o único representante credivel da química orgânica francesa $^{54}$. Em 1865, Berthelot montou finalmente um laboratório de investigação no Collège de France, criando uma escola que se desenvolveria rapidamente a partir dos anos 70 devido, principalmente, a três factores: a criação da Ecole Pratique des Hautes Études (EPHE), a sua mudança da área da química orgânica para a termoquímica e a eleição para a Académie des Sciences em 1873, secção de física.

Embora a EPHE tenha sido criada no fim do Segundo Império a sua acção veio a desenrolar-se na Terceira República. Tratava-se de uma superestrutura que passou a governar oficialmente a investigação científica, no quadro do Ministério da Instruçāo. Fundamentalmente, reconheceu os laboratórios existentes dando-Ihes enquadramento legal. Devi- 
do à sua forte ligação aos meios republicanos e jornalísticos, Berthelot veio a beneficiar como nenhum dos seus colegas deste organismo, obtendo fundos que the permitiam contratar discípulos os quais, neste caso, poderão ser designados mais apropriadamente assistentes. Dividiam-se por três categorias, os préparateurs du cours, exclusivamente com tarefas de ensino, mas que como volontaires - categoria onde se incluiam também os estrangeiros - podiam realizar investigação, e os préparateurs-adjoints que apenas se dedicavam à investigação. No total identificaram-se 51 dos quais 15 estrangeiros. Depois da sua eleição para a Académie, Berthelot sofisticou o método de recrutamento, indo buscar os licenciados melhor classificados das grandes écoles, que eram depois contratados. Normalmente, permaneciam no laboratório do mestre cerca de dois anos, o tempo para preparar um doutoramento, sendo depois colocados em faculdades de província ou, eventualmente, em Paris. Estas colocações eram obtidas com o patrocínio de Berthelot que habilmente usava as suas influências. A perspectiva de um salário, um doutoramento praticamente garantido e, no final, um emprego foram razões de peso na angariação de assistentes. Todavia, alguns destes viriam mais tarde a revelar terem preferido escolher outro mestre ${ }^{55}$.

Berthelot foi retratado como um mestre exigente, impondo continuamente aos discípulos a repetição das mesmas experiências ${ }^{56}$. 0 ambiente do laboratório é descrito como monótono e aborrecido, tendo os discípulos de realizar tarefas consideradas de "interesse geral" ou, mais propriamente, do interesse pessoal de Berthelot ${ }^{5}$. Não Ihes era permitida qualquer originalidade $e$ as teses de doutoramento mais não faziam do que corroborar à exaustão as teses do mestre. Deville chegou a manifestar essa crítica quando foi chamado a ser membro de júris. Posteriormente, vários dos assistentes de Berthelot vieram a rejeitar as ideias do mestre, embora cautelosamente devido à posição influente deste, no quadro da Terceira Republica: Inspector do Ensino Superior (1876-1888), Ministro da Instrução (1886-1887), Mi- nistro dos Negócios Estrangeiros (1895-1896), entre outros.

Fortemente marcado por uma ideologia de inspiração positivista, Berthelot tinha uma visāo cumulativa do conhecimento científico expressa não só no seu trabaIho, mas também nas suas obras de história da química (1885-1907). Era um empirista profundamente descrente de teorias e rejeitava os átomos porque não podia vê-los nem contá-los. A teoria atómica foi por ele banida do ensino oficial, situaçẫo que se manteve até próximo da Primeira Guerra Mundial. Defendia os equivalentes, e pretendia unificar a química pelas regras da química mineral, i.e., com base no dualismo de Berzelius. Rejeitava a termodinâmica e defendia os princípios de uma termoquímica que ao tempo era já, nacional e internacionalmente, posta em causa ${ }^{58}$. A investigação da sua escola ocupou-se da química orgânica (1850-1869), da termoquímica (1869-1888) e da química agrícola (1885-1907).

Berthelot publicou o número aparatoso de cerca de 1600 títulos, e só muito poucos discípulos publicaram em conjunto com ele. A maioria não publicava enquanto preparava o doutoramento. A sua escola não detinha o controlo de nenhuma revista e as revistas mais usadas eram os Comptes Rendus e os Annales de Chimie $^{\text {va }}$. A intervenção da escola de Berthelot na Société Chimique esteve quase confinada ao próprio mestre que ocupou a presidência várias vezes, o mesmo acontecendo com quatro dos seus discipulos mais chegados.

A escola de Berthelot permaneceu confinada ao contexto nacional onde este Ihe poderia garantir uma existência segura. A participação em eventos internacionais e 0 intercâmbio com outros paises foi muita limitada, situação já anunciada pela ausência de Berthelot no Congresso de Karlsruhe, em 1860, que embora dominado pelos atomistas contou com a presença de Deville e do próprio Dumas.

\section{Conclusões}

A influência de certos individuos e escolas no patrocínio de jovens para lugares no ensino superior é particularmente grande, em França. $O$ destino de um estudante de ciência depende fortemente do líder que ele escolhe seguir, e há suficiente coesão entre os membros de uma escola para torná-la num corpo efectivo.

(James Mason Crafts, 1900) ${ }^{61}$

Em França, a emergência de escolas de investigaçāo em química representou uma tentativa de integrar a investigação nas universidades como uma actividade oficialmente reconhecida, e foi independente das reformas governamentais do ensino superior. Todo este processo viria a conduzir a uma normalização da investigação no que respeita a métodos, teorias e até a ideologias científicas.

No que se refere à organização, começando pela escola de Cahours, a sua pequena dimensão reflecte um caso extremo em que a iniciativa pessoal e a bonomia associadas à personalidade do mestre quase fizeram dela uma pequena e confortável família, conforme testemunham os discípulos. Esta característica esbater-se-á com a crescente institucionalização das escolas. As escolas de investigação de Cahours e de Deville, e apesar das dimensões consideráveis desta última, constituem bons exemplos de uma estrutura de organização quase familiar. Juntas caracterizam o período mais influente de Dumas, durante o Segundo Império, definindo um estilo de liderança e de patrocínio dos discípulos de cariz marcadamente paternalista

Este comportamento abrangia vários domínios que iam da supervisão da investigação, à publicação em que o mestre era quase sempre co-autor, conselhos e apoio em matérias do foro privado dos discípulos, até ao patrocínio de carreiras científicas. Nomeadamente, a transmissão de cargos de ensino era feita como se tratasse de uma herança, em que os pupilos mais velhos tinham prerrogativas de sucessão.

Quando se passa para Pasteur e, finalmente para Berthelot, a estrutura quase familiar adquire gradualmente outras característica que acompanham as mudanças políticas no país. 
No entanto, as escolas de Cahours e Deville, apresentavam já o germe daquilo que viria a ser a progressiva burocratização das escolas: a ligação do estágio de investigação a uma actividade de ensino remunerada, bem com a segurança de emprego depois da conclusão do doutoramento. Com Deville, em particular, esta tendência é já bastante acentuada.

No caso de Pasteur, a sua presença forte ainda que indirecta corresponde a um ponto de viragem em que o papel do mestre se torna cada vez mais abstracto. Os discípulos seguiam cegamente um mestre idealizado, um génio desinteressado dedicado ao bem da humanidade. Mais tarde, a criação do Institut Pasteur em Paris tornou-se o centro da sua organização, destinada a espalhar pelo mundo métodos e práticas científicos através das muitas delegações que abriram em vários países. A dimensão internacional do empreendimento de Pasteur não é sintoma de uma posiçăo advogando o internacionalismo da ciência - Pasteur assumia com frequência posições de extremo nacionalismo mas inscreve-se, perfeitamente, na tradição francesa de uma mission civilisatrice.

Finalmente, Berthelot, o símbolo cientifico "canonizado" pela Terceira Republica, como atestam os seus funerais nacionais no Panthéon, e as pomposas homenagens que Ihes sucederam, não personifica nem o mestre paternal típico do Segundo Império, nem o mestre idealizado como Pasteur. Especialmente depois dos anos 70, a sua presença controladora assemelha-se à de um empregador do estado dispondo de um aparelho administrativo e burocrático que usa na perfeição. Os discipulos foram reduzidos ao papel de funcionários públicos, tendo de aceitar sem questionar o regime da escola, de forma a não pôr em causa um salário e um doutoramento praticamente garantido. 0 doutoramento foi ele próprio burocratizado, convertendo-se numa formalidade que precedia um lugar na carreira académica, assegurado pelos auspicios do patron. A criatividade e originalidade inerentes à investigação científica ficaram assim seriamente comprometidas.

No que toca ao financiamento, pode concluir-se que o lançamento das escolas, especialmente de Deville, Pasteur e de Berthelot dependeram da aquiescência dos mestres com os regimes políticos. Apesar de terem Dumas como intermediário, a criação das escolas de Deville e Pasteur teria sido impossivel sem a adesão destes ao Segundo Império. A investigação era conforme às políticas de Napoleâo III, que queria desenvolver as ciências aplicadas à resolução de problemas económicos. Financiando directa e indirectamente as pesquisas destes dois mestres, o Imperador assumia ele próprio o papel de patrono. Este financiamento era complementado por fundos ocasionais provindos da Académie des Sciences e do Ministério da Instrução, denotando uma política de investigação baseada no tráfico de influências, i.e., sob a égide de Dumas e de Napoleão III enquanto mediadores.

Com Berthelot a situação muda especialmente pelos beneficios que colheu da criação da EPHE, embora muitos aspectos permanecessem, especialmente o tráfico de influências. A EPHE enquadrou legalmente a investigação cientifica no sistema universitário, ao incorporar as escolas no dispositivo da administração central. A Terceira República viria assim a transformar a iniciação na investigação em funcionalismo público.

Em todo este trajecto, a escola de Wurtz apresenta-se como uma singularidade no panorama francês, aproximando-se do modelo de Liebig. 0 financiamento da escola baseou-se, essencialmente, nas propinas pagas pelos discipulos. Estes eram na sua maioria estrangeiros e alsacianos pertencentes a uma elite de contornos europeus que aliava, por vezes, certas afinidades intelectuais e culturais à capacidade económica. A passagem por um laboratório de investigação era vista como parte de uma formação avançada e não como um emprego. Os contactos e a cooperação internacionais eram grandemente valorizados e, de uma maneira geral, os estrangeiros de regresso aos seus países fundaram, eles próprios, escolas de investigação. A iniciativa individual era encorajada e as viagens faziam parte da agenda da formação de um investigador, mostrando os discípulos interesses em outras áreas como a música, as línguas, a literatura, a arte, a história e a filosofia. Do ponto de vista da teoria química e da prática laboratorial, a escola estava em sintonia com os principais centros de produção europeus na área da química orgânica.

No que se refere ao mestre, pode dizer-se que conseguiu conciliar a sua visão da ciência, com um percurso que não hostilizou internamente os cânones da oficialidade científica, mas que apostou fortemente na arena internacional. Deste modo, foi possivel a sobrevivência e desenvolvimento de uma escola que tanto pelas características de minoria religiosa, cultural e étnica dos seus membros, como pelas opções teóricas no quadro da quimica, muito dificilmente teria conseguido manter-se.

\section{Notas}

1 John W. Servos, "Research Schools and Their Histories", Osiris, 8 (1993), 3-15.

2 J. B. Morrel, "The Chemists Breeders: The Research School of Liebig and Thomas Thomson," Ambix, 9 (1972), 1-46.

${ }^{3}$ G. L. Geison, 'Scientific Change, Emerging specialties and Research Schools, " History of Science, 19 (1981), 20-40.

4 J. Fruton, "The Liebig Research Group - A Reappraisal," Proceedings of the American Philosophical Society, 132 (1988), 1-66.

${ }^{5}$ E. S. Shaffer, "Romantic Philosophy and the Organization of the Disciplines: The Founding of the Humboldt University," in A. Cunningham; N. Jardine, edits., Romanticism and the Sciences, Cambridge, 1991 , pp.38-54.

6 W. Farrar, "Science and the German University System, " in M. P. Crosland, edit., The Emergence of Science in Western Europe, Londres, 1975, pp. 179-192.

7 Bildung significa, aproximadamente auto-formação segundo uma visão unificada do saber, uma tradição muito valorizada pela cultura germânica. W. Bruford, The German Tradition of Self-Cultivation. "Bildung" from Humboldt to Thomas Mann, Cambridge 1975. 
8 Por exemplo Novalis (Friedrich von Hardenberg) descreve nesta obra um velho sábio orientando os seus discípulos na recoIha de folhas e pedras por forma a que estes experienciassem a busca de analogias na natureza...

${ }^{9}$ Shaffer, op. cit. (), p. 45.

10 Ibid.

$11 \mathrm{H}$. Helmoltz, "La Liberté Académique dans les Universités Allemandes," Revue Scientifique, 14 (1878), 813-820.

12 Deverá referir-se que, no séc. XIX, Portugal não participou deste movimento europeu de criaçâo de escolas de investigaçẫo que haveria de propagar-se pouco depois aos EUA, apesar de alguns quimicos portugueses como Agostinho Vicente Lourenço que viria a ser professor da Politécnica de Lisboa, e de Roberto Duarte da Silva, que acabaria por permanecer em França, terem feito a sua formação na escola de investigação de Wurtz, em Paris.

13 R. Low, "The Progress of Organic Chemistry during the Period of German Naturphilosophie, "Ambix, 27 (1980), 1-10.

14 Morrell, op. cit. (3).

15 L. Klosterman, "A Research School of Chemistry in the Nineteenth-Century: Jean Baptiste Dumas and his Research Students," Annals of Science, 42 (1985), 1-40 (1. a parte); 40-80 (2. ${ }^{a}$ parte).

160 estudo detalhado destas escolas e, em particular, a de Adolphe Wurtz, encontra-se em A. Carneiro, The Research School of Chemistry of Adolphe Wurtz, Paris, 1853 -1884, Tese de Doutoramento, Universidade de Kent (G. B.), Unit for the History, Philosophy and Social Relations of Science, 1992.

17 L. Figuier, "Nécrologie Scientifique du Dr. Quesneville, "L'Année Scientifique et Industrielle, 33 (1899), 609-610.

$18 \mathrm{~A}$ razão da inclusão de Pasteur prende-se com o facto de tanto o próprio como os seus contemporâneos considerarem que a sua investigação, como é sabido de âmbito muito vasto e abrangendo áreas essencialmente da microbiologia, se incluia do domínio da química fisiológica. Além disso, Pasteur competia com os colegas químicos no que respeita a fundos para a investigação e lugares no ensino superior.

19 Carneiro, op. cit. (16), p. 25-26

20 Cumul, era o regime de acumulaçã̃o de vários posiçôes no ensino que em parte se explica pelos salários baixos pagos mas que também tinha o efeito de aumentar a influência e controlo de certas personalidades. Pasteur opôs-se-Ihe publicamente com vee- mência. Suppléance, era o processo pelo qual um protégé substituia o professor titular de uma cadeira mediante o pagamento de uma fracçẫo do salário deste.

21 Carneiro, op, cit. (16), p. 27.

22 Cahours era amigo de Charles Gerhardt que com Auguste Laurent era adepto do atomismo. Enfants terribles de Dumas, e conhecidos por les deux, esse facto muito terá contribuido para que este os destinasse a universidades de província onde se viram quase impedidos de prosseguir as suas investigaçōes. Ver, por exemplo, cartas de Gerhardt a Cahours, Paris, Académie de Sciences, Dossier Gerhardt.

${ }^{23}$ De notar que os discipulos de Wurtz admiravam os trabalhos de Cahours e dos colegas que com ele trabalhavam. A. Gautier, "Biographies Scientifiques. L'Oeuvre de M. A. Cahours, " Revue Scientifique, 49 (1891), 385-287 e E. Grimaux, "Biographies Scientifiques. L'Oeuvre d'Auguste Cahours,' Revue Scientifique, 49 (1892), 97-101, por exemplo. 24 J.-B. Dumas, Discours et éloges académiques, Paris, 1885, pp. 307-308.

25 Carneiro, op. cit. (16), p. 34.

26 Carneiro, op. cit. (16), p. 19.

27 Carneiro, op. cit. (16), pp. 35-36.

28 Carneiro, op. cit. (16), pp. 36-37.

29 Deville produziu em larga escala barras maciças de alumínio que foram expostas na Exposição de Paris de 1855. Napoleão III também desejava ver a suas tropas a desfilar com capacetes de aluminio. E. Oesper; P. Lemay, "Henry Sainte-Claire Deville, 1818-1881, " Chymia, 3 (1950), 205-221.

30 Carneiro, op. cit. (16), pp. 77-84.

31 Carneiro, op. cit. (16), pp. 84-88

32 L. Foucault, "Feuilleton Académie des Sciences," Journal des Débats Politiques et Littéraires, 10 de Janeiro de 1850.

33 R. Fox, "Presidential Address: Science, Insdustry and Social Order in Mulhous,", British Journal for the History of Science, 17 (1984), 127-168; P. Leuillot, L'A/sace au début du XIXème siècle: Essais d'histoire politique, économique et religieuse, Paris, 1959-1960; Carneiro, op. cit. (16), pp. 111 -134; A. Carneiro; N. Pigeard, "Chimistes alsaciens à Paris au 19ème siècle: un réseau, une école?, " Annals of Science, 54 (1997), 533-546.

34 Scheurer-Kestner, ao tempo Senador, seria o responsável pela abertura do caso, empenhando-se decisivamente na reabilitação da vítima. P. Ory; J.F. Sirinelli, Les intellectuels en France de l'affaire Dreyfus à nos jours, Paris, 1986
35 Carta a Dumas, 15 de Fevereiro 1864 , Paris, Archives de l'Académie des Sciences, Dossier Wurtz.

36 Procès Verbaux de l'Assemblée des Professeurs de la Faculté de Médecine, Paris. Archives Nationales (AJ/16/6255*); M. Lipinska, Histoires de Femmes Médecins, Paris, 1900.

37 Carneiro, op. cit. (16), pp. 73-76.

38 Carneiro, op. cit. (16), pp.144-146.

${ }^{39}$ A. Carneiro, "Adolphe Wurtz and the Atomism Controversy, " Ambix, 40 (1993), 75-95; A. Carneiro; N. Pigeard, "L'Atome en Jeu," Comptes Rendus de l'Académie des Sciences de Paris, [2], 323 (1996), 421$-424$.

40 Carneiro, op. cit. (16), Apêndice, Tabela 1.

41 Carneiro, op. cit. (16), pp.230-239

42 Carneiro, op. cit. (16), 239-245.

43 Esta associação foi criada por um discípulo de Goethe, o naturalista Lorenz Oken cuja obra na área da anatomia transcendental era particularmente cara a Wurtz. Oken havia sido proclamado em Estrasburgo o "pai" das sociedades cientificas itinerantes. Obviamente, com a agressāo prussiana a inspiraçăo germânica não poderia ser agora invocada.

44 Carneiro, op. cit. (16), 246-250; G. Hacquard, Hištoire d'une instituion française: L'Ecole alsacienne. Naissance d'une école libre, 1871-1891, Paris, 1982.

45 Carneiro, op. cit. (16), 250-253.

46 Carneiro, op. cit. (16), pp. 253-256.

47 Carneiro, op. cit. (16), pp. 36.; G. L. Geison, Artigo Pasteur, in C. C Gillispie, edit., Dictionary of Scientific Biography, N. York. 1970-1980, vol. 10, pp. 350-416

${ }^{48}$ E. Duclaux, "Le laboratoire de M. Pasteur," in Ecole Normale Supérieure. Livre du centenaire, 1795-1895, Paris, 1896; C. D'Eschevannes, Pasteur, sa vie, sa foie, son oeuvre, Paris, 1934, pp. 192-193; R. Dubos, Louis Pasteur freelance of science, Londres, 1951, p. 60; B. Latour, The Pasteurization of France, Cambridge Mass., 1988.

49 Pasteur deixou instruções para não ser sepultado no Panthéon, por este estar conotado com a República. O seu túmulo na cripta do Institut Pasteur está rodeado de quatro anjos representando a fé, a esperança, a caridade e a ciência.

50 Geison, op. cit. (48), p. 385.

51 Dubos, op. cit. (48), p. 91. Pasteur ficou chocado quando soube que o Dr. Grancher, que com ele colaborou nos estudos da raiva. 
tinha um sofá e uma cadeira de baloiço no laboratório.

52 Dubos, op. cit. (48), p. 60; Duclaux, op. cit. (48), p.465.

53 Duclaux, op. cit. (48), p. 461

54 "Sur la création d'une chaire de chimie organique au Collège de France," Journal Général de I'Instruction Publique, 26 de Dezembro de 1863.

55 Carneiro, op. cit. (16), pp. 50-52.

56 Carneiro, op. cit. (16), p. 49.

57 Ibid.

58 Nomeadamente pelo dinamarquês Julius Thomsen, e por Favre, Silberman e Pierre Duhem, entre outros. R. G. A. Dolby, "Thermochemistry versus Thermodynamics: the 19th century Controversy," History of Science, 22 (1984), 375-400; V. Schellar, "Thermochemistry and the Third Law of Thermodynamics," Chymia, 11(1966), 96-124.; J. Jacques, Berthelot. Authopsie d'un mythe, Paris, 1987.

59 Berthelot atribuiu à síntese orgânica um significado filosófico profundo proclamando-se o seu "inventor." Tinha dela uma concepção aditiva. Aplicou os seus princípios à síntese de compostos muito simples cuja preparação envolvia apenas um único passo. Obviamente que a sintese de compostos mais complexos era impossivel neste contexto e dai que tenha mudado para a termoquímica afirmando, todavia, que o trabalho de revelar os princípios sobre os quais assenta a sintese orgânica já estava feito. M. Berthe- lot, Chimie organique fondée sur la synthèse, Paris, 1860.

60 A primeira viu-se forçada a impor restrições à extensão exagerada dos seus trabaIhos e Wurtz, entāo editor dos Annales de Chimie acusou-o de publicar o mesmo artigo várias vezes, aconselhando-o a ao menos "rejuvenescer" os artigos antes de os submeter para publicação. Carneiro, op. cit. (16), pp. 56 e 72, nota 163.

61 J. M. Crafts (1839-1917), químico americano discipulo de Wurtz entre 1862-66, altura em que travou amizade com o químico alsaciano, Charles Friedel (1832-1899), um dos discípulos mais chegados de Wurtz.. As reacções de Friedel-Crafts são bem conhecidas de todos os químicos orgânicos.

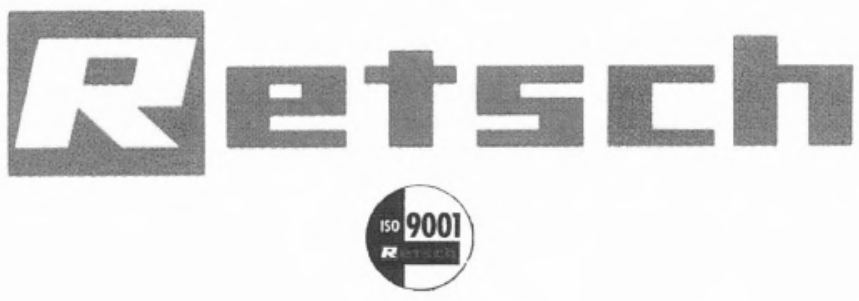

Moinhos
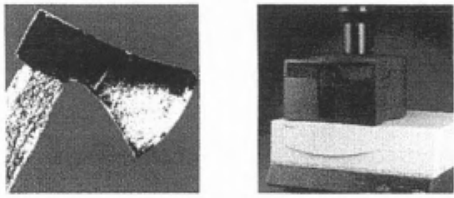

Agitadores de peneiros/peneiros
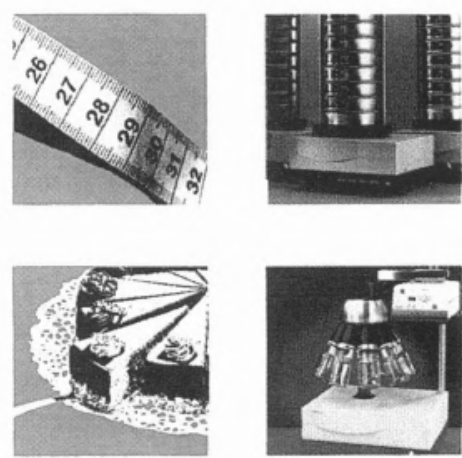

\section{Análise granulométrica automática CAMSIZER / Crystalsizer}

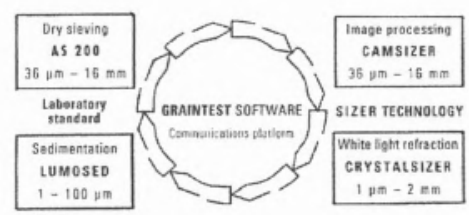

Peça-nos o contacto do agente mais próximo, através dos telefones:

$$
\text { 21-352 } 7293
$$

Campo Mártires da Pátria, 109
22-618 4232

0 Impartador Exclusiua 